\title{
Gerhard Jacob, o cientista e o gestor acadêmico
}

\author{
Gerhard Jacob, the scientist and academic manager \\ Carlos Alberto dos Santos ${ }^{*}$ \\ ${ }^{1}$ Universidade Federal do Rio Grande do Sul, Instituto de Física, Porto Alegre, RS, Brasil
}

\begin{abstract}
Recebido em 02 de dezembro de 2019. Revisado em 16 de janeiro de 2020. Aceito em 30 de janeiro de 2020
No seu sexagésimo ano de fundação, o IF-UFRGS já não conta mais com seus três principais criadores. Theodor Maris faleceu em 20 de agosto de 2010, Darcy Dillenburg em 15 de janeiro de 2015 e Gerhard Jacob em 25 de outubro de 2018. Dos três, foi Gerhard aquele com quem tive maior proximidade pessoal. Digitalizei parte do seu acervo documental, e havíamos planejado escrever um artigo em colaboração a partir de suas reminiscências, um texto de 80 páginas que ele havia me passado para ler, comentar e avaliar que destino lhe seria dado. Circunstâncias de nossas vidas profissionais impediram que o projeto fosse executado a tempo. No presente trabalho, o perfil biográfico do prof. Gerhard será apresentado a partir de informações relevantes contidas naquele depoimento, informações coletadas nos arquivos do IF-UFRGS e nos arquivos pessoais do professor, bem como informações extraídas de uma entrevista por ele concedida a este autor em 2015. É apresentada uma breve análise da contribuição científica do prof. Gerhard e de sua atuação como gestor, na UFRGS e em várias instituições externas, sobretudo o CNPq, do qual foi membro do Conselho Deliberativo e seu presidente.
\end{abstract}

Palavras-chave: Gerhard Jacob, Física Nuclear, IF-UFRGS

In its 60 th year of foundation, the IF-UFRGS no longer has its three main creators. Theodor Maris passed away on August 20, 2010, Darcy Dillenburg on January 15, 2015 and Gerhard Jacob on October 25, 2018. Of the three, Gerhard was the one with whom I had the closest personal proximity. I digitalized part of his documentary collection, and we had planned to write a collaborative article from his reminiscences, a text of 80 pages he had given me to read, comment, and evaluate what destination would be given to it. Circumstances of our professional lives prevented the project from being executed on time. In the present work, the biographical profile of prof. Gerhard will be presented from relevant information contained in that memory, information collected from the IF-UFRGS files and from the professor's personal files, as well as information extracted from an interview he gave to the present author in 2015. A brief analysis of the scientific contribution of prof. Gerhard and his role as manager at UFRGS and various external institutions, especially CNPq, of which he was a member of the Deliberative Council and its chairman.

Keywords: Gerhard Jacob, Nuclear Physcs, IF-UFRGS

\section{Introdução}

É muito frequente que uma organização apresente traços do caráter de seus principais líderes. O caráter que se destaca aqui é aquele pertinente à missão institucional da organização. É impossível descrever a história do Instituto de Física da UFRGS sem que se perceba a marcante presença de Gerhard Jacob. Ao seu lado, desde o início, o parceiro de toda uma vida, Darcy Dillenburg. Os dois formavam o que um dia denominei de a dupla hélice do IF-UFRGS [1, p. 89-108], e para ficar na metáfora biológica, eles funcionavam com a energia vinda da ATP personificada em Theodor August Johannes Maris [2]. Essa tríplice colaboração, que nos corredores do IFUFRGS era por alguns identificada como a santíssima trindade, teve início com a criação do Instituto, em 1959, mas Gerhard e Darcy já vinham de uma convivência estudantil, entre 1952 e 1957, uma etapa que se mostraria

*Endereço de correspondência: cas.ufrgs@gmail.com fundamental para a história do IF-UFRGS. Esse era o período em que a pesquisa em Física na UFRGS dava seus primeiros passos, no icônico Centro de Pesquisas Físicas da URGS1] [3], no qual Gerhard e Darcy tiveram participação ativa, mesmo antes de concluírem seus cursos universitários. Na verdade, como veremos mais adiante, logo depois do bacharelado em Física, Gerhard foi contratado como Instrutor de Ensino na Faculdade de Filosofia, o que lhe deixou pouco tempo para se envolver com o CPF. Ao contrário de Darcy, que chegou a ser secretário informal do Centro. Na Fig. 1 os dois em suas mesas de trabalho no CPF.

Apresentarei neste artigo elementos da biografia acadêmica de Gerhard Jacob, que na noite de 24 de outubro de 2018 faleceu aos 88 anos de idade, três anos e nove meses depois do falecimento de seu grande companheiro de vida

\footnotetext{
${ }^{1}$ URGS: Universidade do Rio Grande do Sul. Só depois de 1968 é que ela transformou-se em Universidade Federal do Rio Grande do Sul.
} 


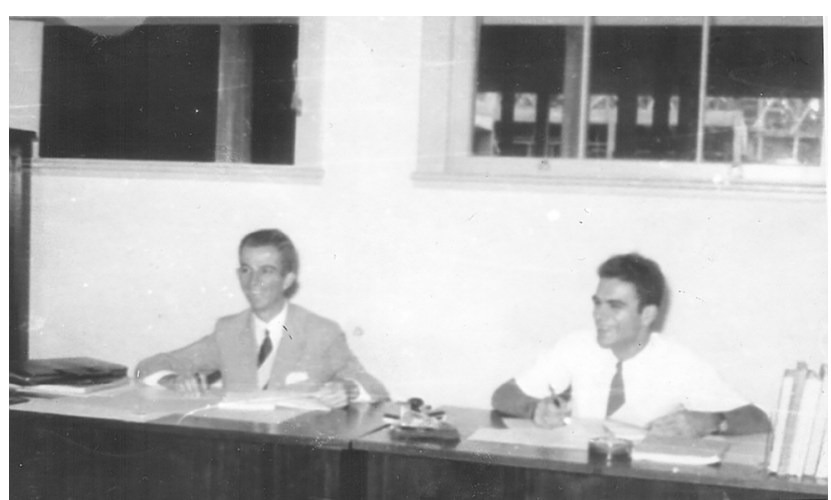

Figura 1: Gerhard (à direita) e Darcy, no CPF, anos 50. Foto do acervo do IF-UFRGS)

acadêmica, Darcy Dillenburg. Farei este relato a partir de documentos disponíveis nos arquivos do IF-UFRGS, de comunicações pessoais que trocamos ao longo de anos, de uma entrevista que ele me concedeu em 2015, e sobretudo a partir de um texto que ele vinha preparando há anos, por ele denominado Reminiscências, cuja cópia de 21 de março de 2015 contém 83 páginas. Ele não tinha certeza de como fazê-las públicas. Propus-lhe publicarmos como uma entrevista, mas em seu habitual nível de exigência ele tinha suas dúvidas, expostas em mensagem enviada em 7 de abril de 2015, sobre o interesse de alguma revista publicar algo tão local. Gerhard não tinha ideia da dimensão histórica de seu depoimento.

Depois dessa mensagem fui arrastado pela roda-viva da minha atividade acadêmica para outros objetivos e não voltamos a conversar sobre o assunto. Então, mais que uma homenagem a Gerhard Jacob e o cumprimento de uma dívida pessoal, este relato que aqui apresento é o melhor que eu posso fazer para a historiografia da Física no Rio Grande do Sul. E para ser fiel ao sentimento de amizade que Gerhard nutria em relação a Darcy Dillenburg, manterei aqui as referências aos dois, do mesmo modo que Gerhard o fez em suas reminiscências.

Embora seja impossível separar o cientista do gestor no início da carreira acadêmica de Gerhard, apresentarei aqui o cientista e o gestor em relatos separados, apenas como uma estratégia metodológica, mesmo que em muitas oportunidades esses dois tipos de atividade tenham ocorrido simultaneamente.

\section{O estudante}

Nascido em Hanover, Alemanha, em 5 de novembro de 1930, Gerhard chegou ao Brasil na companhia de seus pais em 1936. Aqui foi alfabetizado em alemão por sua mãe. A família fixou residência em Giruá, então distrito de Santo Ângelo (RS), onde seu pai exerceu a profissão de médico. Em 1943 foi para Porto Alegre para fazer os estudos secundários (ginasial e científico) no Instituto Porto Alegrense, mais conhecido como Colégio IPA, onde teve os primeiros incentivos para estudar Física.
Foi seu professor de química, Tuiskon Dick, o principal responsável por essa orientação. Anos depois, Tuiskon, já professor de química da UFRGS, foi Vice-Reitor e sucessor de Gerhard, quando este afastou-se da reitoria para ocupar a presidência do CNPq.

Em 1950, foi aprovado nos vestibulares para os cursos de Física na Faculdade de Filosofia e de Arquitetura (em processo de fusão entre a Escola de Engenharia e o Instituto de Belas Artes) da URGS. Não lhe foi permitido fazer os dois cursos e Gerhard decidiu cursar Física. No ano seguinte é aprovado no vestibular para o curso de Matemática da mesma Faculdade de Filosofia, onde era permitido ser aluno em mais de um curso. Concluiu o bacharelado em Física em 1952. Em 1953 concluiu a licenciatura em Física e o bacharelado em Matemática. No ano seguinte concluiu a licenciatura em Matemática.

Aqueles que ingressaram na universidade depois dos anos 1970 talvez fiquem confusos com as informações acima. Como concluir o bacharelado em três anos e a licenciatura no ano seguinte? Até a reforma universitária de 1968, os cursos da Faculdade de Filosofia da URGS (ainda não era UFRGS) eram divididos em três anos de estudos científicos específicos, o que conferia o grau de bacharel, e um ano de estudos pedagógicos, o que conferia o grau de licenciado. Esse sistema ficou conhecido como sistema $3+1$. Muitos alunos da Física mais inclinados para a pesquisa e o ensino universitário, só concluíam o bacharelado.

Logo depois do bacharelado, e alguns meses antes de obter a licenciatura em Física, Gerhard foi contratado como Instrutor de Ensino Superior da cátedra de Física Teórica e Superior. Para usar a notação moderna pós-68, era uma espécie de Auxiliar de Ensino. Em janeiro de 1956, Gerhard é indicado pela Faculdade de Filosofia, juntamente com Darcy Dillenburg, para fazer um curso de férias em Energia Nuclear na USP, durante os meses de janeiro e fevereiro. Esse é um momento de extrema relevância na vida estudantil de Gerhard. Embora auxiliar de ensino em uma cátedra universitária, sua vivência científica era absolutamente nula, como ele mesmo relata em diversas ocasiões [1, p. 89-108].

O objetivo do curso era selecionar integrantes para a equipe que iria instalar o primeiro reator nuclear no Brasil, na Cidade Universitária da USP. Durante esses dois meses conviveram com Marcello Damy de Souza Santos, José Goldemberg (ambos físicos experimentais), Paulo Saraiva de Toledo (teórico) e Rômulo Ribeiro Pieroni (Física médica), e participaram de cursos de Física de Nêutrons e de experiências em Física Nuclear.

Convencidos de seus despreparos, Gerhard e Darcy receberam, com inenarrável surpresa, a notícia de que tinham sido selecionados para trabalhar no projeto do reator nuclear. Em julho de 1956, mudaram-se para São Paulo, com bolsa do CNPq, para iniciarem seus estudos avançados de Física. O que se viu depois, é que o aproveitamento nesses estudos ultrapassou todas as expectativas, mas não sem percalços. Em primeiro lugar porque deram 
a Gerhard uma tarefa experimental, para a qual ele não tinha a menor aptidão. O excelente físico teórico no qual se transformou não poderia ter o mesmo sucesso em um laboratório.

Sob orientação de Marcello Damy, Gerhard e Ewa Wanda Cybulska ficaram encarregados da realização de medidas da distribuição de nêutrons de uma fonte de Ra-Be. Ele não lembra se a distribuição era angular ou de energia. Depois de uns três meses de trabalho eles conseguiram, com o apoio da oficina mecânica do Bétatron, montar o dispositivo para as medidas. Foi quando Gerhard descobriu que naquele momento é que o trabalho iria começar. Passaria mais uns dois meses medindo. Não suportou o choque epistemológico e encerrou ali sua carreira de físico experimental.

Foi pedir socorro ao físico teórico Paulo Saraiva de Toledo, que trabalhava com Física de nêutrons, e já orientava Darcy. Saraiva sugeriu que eles fizessem o doutorado na Faculdade de Filosofia da USP, no icônico endereço da rua Maria Antônia, 294. No $4^{\circ}$. andar funcionava o Departamento de Física, chefiado por Mário Schenberg. O doutorado era no estilo europeu, tese e seminários orientados por um físico experiente, mas havia um prérequisito: um ano de especialização. Foi aí que Gerhard aprendeu Mecânica Quântica, Física Nuclear, Mecânica Analítica, Eletromagnetismo e Termodinâmica. Durante a noite ele fazia a especialização, e durante o dia trabalhava no já recém-criado Instituto de Energia Atômica (IEA), atualmente IPEN, sob orientação do prof. Paulo Saraiva. Essa atividade no IEA resultou nos dois primeiros trabalhos científicos de Gerhard ${ }^{2}$, publicados nos Anais da Academia Brasileira de Ciências (Fig. 2).

Esses trabalhos também foram aceitos para apresentação oral na Segunda Conferência Internacional das Nações Unidas para Usos Pacíficos da Energia Nuclear. Mas, durante esse evento Gerhard já era professor na Faculdade de Filosofia da URGS, conforme veremos mais adiante.

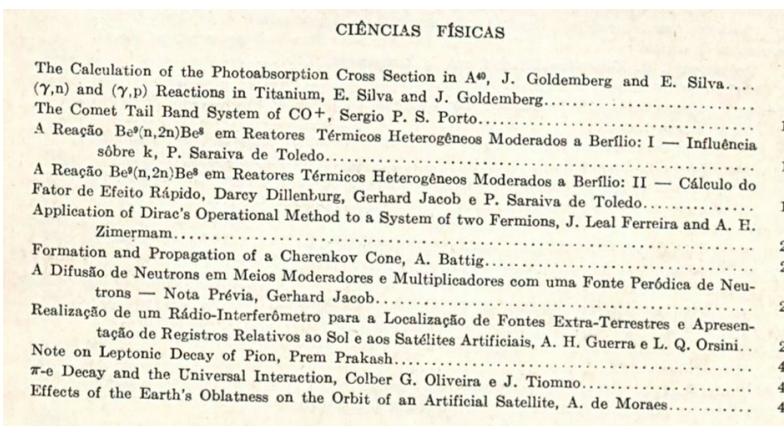

Figura 2: Parte do sumário do volume 30 , número 1 (1958) dos Anais da Academia Brasileira de Ciências. Extraída de http://memoria.bn.br/DocReader/docreader. aspx?bib=158119\&pesq= em $12 / 1 / 202 \mathrm{C}^{3}$

\footnotetext{
2 Nem Gerhard, nem Darcy colocaram esses trabalhos em suas listas de publicações.
}

Em novembro ou dezembro de 19574 quando Gerhard e Darcy discutiam seus possíveis programas de doutorado na USP, uma visita inesperada alterou completamente os rumos de suas vidas. Em um fim de semana chegou a São Paulo Ary Tietböhl, com um convite do então Diretor da Faculdade de Filosofia da URGS, Luiz Pilla, para Gerhard e Darcy assumirem as disciplinas de Física Geral e Experimental e Física Teórica Superior, cujos titulares iriam se aposentar em breve. Para motivá-los a aceitar o convite, Ary Tietböhl informou que:
Havia contatos preliminares do Reitor da URGS, Prof. Elyseu Paglioli, com Ernesto Luiz de Oliveira Junior, futuro Presidente da Comissão Supervisora dos Institutos - CO- SUPI [1, p. 30-77], para a criação de dois institutos: um de Física e um de Matemá- tica (de fato, a proposta era a de um único instituto, de Física e Matemática, mas que Paglioli transformou em dois, persuadindo a COSUPI).

A resposta imediata dos dois foi negativa, pois queriam terminar a formação na USP. Na segunda-feira, ao relatarem o ocorrido a Saraiva, levaram uma "carraspana". Como eles tiveram a coragem de rejeitar um convite para assumir uma cátedra na URGS? Com o mais alto cargo da carreira acadêmica eles teriam a oportunidade de trazer professores visitantes para a URGS, teriam a oportunidade de se afastarem para estágios no exterior, onde completariam suas formações em melhores condições do que como estudantes de doutorado na FFCL da USP. Finalmente, teriam a oportunidade de criar condições para uma boa instituição de Física na URGS.

Então, decidiram aceitar o convite, deixando clara a necessidade de que o Reitor proporcionasse contatos internacionais, tanto na forma de viagens ao exterior (não necessariamente custeadas pela Universidade) como na forma de convites por períodos curtos ou longos a físicos experientes (esses sim, custeados ao menos parcialmente pela Universidade). Posteriormente o Reitor solicitou um compromisso, informal, de não se afastarem ambos simultaneamente.

Em janeiro de 1958, antes da volta a Porto Alegre, lhes foi dada uma oportunidade excelente de aperfeicçoamento: um curso em tempo integral (janeiro e fevereiro) em Física no Instituto Tecnológico da Aeronáutica (ITA), em São José dos Campos. Um dos cursos foi Física Nuclear, ministrado por Marcos Moshinsky. Gerhard e Darcy se ofereceram para redigir as notas do curs ${ }^{5}$ O contato com Moshinsky foi o primeiro que eles tiveram com um físico estrangeiro, já tendo em mente a montagem de uma estrutura de pesquisa na URGS. Como se verá mais adiante, esse contanto teve importância capital na formação dos dois jovens professores.

\footnotetext{
4 Gerhard não lembrava se foi em novembro ou dezembro.

$5 \mathrm{Um}$ exemplar dessas notas encontra-se na biblioteca do IFUFRGS.
} 
Em março de 1958, Darcy assumiu interinamente a cátedra de Física Geral e Experimental da Faculdade de Filosofica da URGS e Gerhard assumiu como Instrutor de Ensino Superior responsável pela cátedra de Física Teórica e Física Superior (substituindo Simões da Cunha que se licenciara). O ex-diretor da Faculdade de Filosofia, Bernardo Geise $\sqrt{6}$ então membro do Conselho Deliberativo (CD) do CNPq, conseguiu uma bolsa para cada um deles, permitindo que se dedicassem às suas atividades em tempo integral.

Entre os dias 14 e 16 de dezembro de 1964, realizou-se o concurso para a Cátedra de Física Teórica e Física Superior, ao qual submeteu-se Gerhard Jacob. A banca examinadora foi constituída pelos seguintes professores: Luiz Pilla (catedrático de Físico-Química e Química Superior), Antônio Rodrigues (Catedrático de Geometria), Jayme Tiomno (Professor Titular de Física Teórica do Centro Brasileiro de Pesquisas Físicas), Juan José Giambiagi (Professor Titular de Física Teórica da Universidade de Buenos Aires) e Oscar Sala (Catedrático de Física Nuclear da Universidade de São Paulo).

O tema da tese de cátedra, Espalhamento Quase Livre e Estrutura Nuclear, transformou-se na principal área de pesquisa em Física Teórica do IF-UFRGS até o final dos anos 1970.

\section{Os primeiros passos como cientista}

Logo que assumiu o cargo de professor na URGS, em março de 1958, Gerhard foi informado de que os trabalhos feitos no IEA haviam sido aceitos para apresentação oral na Segunda Conferência Internacional das Nações Unidas para Usos Pacíficos da Energia Nuclear, que se realizaria em Genebra, em setembro daquele ano. Ele deveria ir para apresentar um dos trabalhos 7 Isso implicava em afastamento logo no primeiro ano de atividade; mas, sendo delegação oficial do governo brasileiro (participaram, entre outros, Otacílio Cunha - Presidente da CNEN, Francisco de Assis Magalhães Gomes, Marcelo Damy, Saraiva e Krumholz), não houve problema com o afastamento, pois era designação oficial do Presidente da República.

Em Genebra, além de participar da Conferência, alguns participantes da delegação visitaram, a convite de Roberto Salmeron, o CERN; foi nessa oportunidade que Gerhard conheceu pessoalmente Salmeron (só o conhecia através de seu excelente livro de Eletromagnetismo para o secundário e através de troca de correspondência sobre o início de pesquisa em Física no Instituto, as quais serão discutidas mais adiante).

As diárias recebidas para a Conferência foram extremamente generosas, e Gerhard aproveitou para ficar na

\footnotetext{
6 Irmão do General Ernesto Geisel, presidente da república entre 1974 e 1979.

7 Darcy Dillenburg poderia ter ido, mas pelo compromisso assumido com o Reitor, de não se afastarem simultaneamente, eles decidiram que Gerhard iria a Genebra e Darcy sairia na oportunidade seguinte.
}

Europa, de setembro a março do ano seguinte, sem prejuízo significativo para o trabalho em Porto Alegre. A ideia era fazer contatos com o objetivo de convencer cientistas experientes a permanecerem um tempo em Porto Alegre orientando as atividades iniciais do instituto de Física que em breve deveria ser criado.

Tentou, por intermédio de Salmeron, um estágio no CERN, mas este estava lotado de cientistas de vários países. Salmeron tentou o Instituto Niels Bohr, mas a situação era a mesma: lotado. Uma boa alternativa imaginada por Salmeron era Heidelberg, onde trabalhava Johannes Hans Daniel Jensen, que dividiu o Prêmio Nobel de Física de 1963 com Maria Goeppert-Mayer, pela elaboração do modelo de camadas do núcleo. Todavia, Salmeron não tinha qualquer contato com o grupo de Heidelberg, e se quisesse ir Gerhard teria que se virar. E ele se virou. Foi para a casa de um tio que morava em Heidelberg e no dia seguinte dirigiu-se ao departamento de Física da universidade de Heidelberg, conhecido como o instituto de Jensen, e pediu para falar com ele. O secretário tentava blindar o chefe, quando este apareceu e perguntou o quê Gerhard queria. Seguiu-se um diálogo no qual Jensen procurou avaliar o nível de conhecimento de Gerhard, e não teve dificuldade em comprovar que era praticamente zero, mas Jensen achou que deveria ajudar aquele brasileiro atrevido. Providenciou uma mesa e disse: agora, vire-se! Essa era uma prática "pedagógica" usual na universidade alemã da época.

Foi a primeira e bem-sucedida experiência internacional de Gerhard, ainda sem doutorado (ou tese de cátedra), sem orientador, e nem sequer com projeto de tese definido. Em colaboração com um estudante de doutorado do instituto, Jörg Eichler, e sob a supervisão de Jensen e Berthold Stech, publicou seu primeiro artigo em revista "indexada". Tratava-se de um trabalho sobre transições quânticas em núcleos isoméricos [4]. Como veremos, um assunto pouco correlacionado com aquele que desenvolveria após a chegada do prof. Maris ao IF-UFRGS.

A atuação de Gerhard deve ter impressionado Jensen, que em janeiro ou fevereiro de 1959 o convidou para ocupar uma vaga de assistente no instituto e com ele fazer seu doutorado. Convite declinado em função do compromisso assumido com a URGS. Compromisso institucional à frente do interesse pessoal.

\section{O professor-gestor: do CPF ao IF}

Ao ingressarem como professores da UFRGS, Gerhard e Darcy começaram uma busca incessante de um físico experiente e de boa formação acadêmica para liderar o projeto científico do IF. Eles já tinham contatos com profissionais desse nível, mas nem todos podiam atender o convite. Os poucos brasileiros disponíveis estavam comprometidos com a criação de suas instituições (CBPF, 
IF-USP) 8 Juan José Giambiagi, embora tenha trabalhado um bom tempo no CBPF, tinha forte compromisso com a Universidade de Buenos Aires. Guido Beck, que encontrava-se no CBPF, era um homem do mundo, não tinha perfil para permanência a longo prazo em um único local. Com esses dois, Gerhard e Darcy mantiveram um estreito contato no final dos anos 1950 e início dos 60, sobretudo com Guido Beck, com quem mantiveram uma correspondência epistolar com mais de 40 cartas entre eles. Aparentemente, a primeira visita de Giambiagi ao CPF ocorreu em 1954, para proferir uma palestra. Na sequência, fez várias visitas até o final dos anos 1960. Em 1964, juntamente com Jayme Tiomno e Oscar Sala, Giambiagi participou da banca do concurso de Cátedra de Gerhard.

De toda a correspondência com renomados cientistas anterior à criação do IF-UFRGS, gostaria de destacar uma carta recebida de Roberto Salmeron, datada em 1 de março de 1958 (Ver Figure s1). O prof. Saraiva, que estava orientando informalmente Gerhard e Darcy, sugeriu que eles convidassem Salmeron para dirigir o futuro IF-UFRGS. Imediatamente eles escreveram para Salmeron. Foi de fato o primeiro convite oficial feito a alguém para liderar o projeto de pesquisa do IF. As outras tentativas não passaram de sondagens em contatos pessoais. Como veremos a seguir, a segunda tentativa, desta vez bem-sucedida, foi um ano depois, com o convite a Theodor Maris.

Em sua resposta, Salmeron, que aparentemente não tinha conhecimento que Gerhard e Darcy eram apenas graduados, refere-se a cartas enviadas por eles em 1 e 2 de fevereiro de 1958. Infelizmente cópias dessas cartas não foram encontradas nos arquivos do IF, nem de posse de Gerhard e Darcy. Por outro lado, há uma carta de Gerard Hepp dirigida a Salmeron, datada em 3 de janeiro daquele ano (Ver Figure S2). Esse contato foi feito paralelamente àquele de Gerhard e Darcy e tinha objetivo levemente diferente. Hepp $[3,5]$ focava o CPF, enquanto Gerhard e Darcy já estavam planejando a criação do IF. Não tenho conhecimento se Salmeron respondeu a Hepp. Cópias de suas cartas não foram encontradas nos arquivos do CPF. De todo modo, a comparação dessas duas cartas tem grande significado histórico porque define o cenário institucional na URGS, e como pensavam algumas das personalidades envolvidas na passagem do CPF para o IF.

O CPF foi absorvido pelo IF, em março de 1959, sem desenvolver qualquer projeto de pesquisa. No entanto, a base da pesquisa em Física Experimental que viria a ser desenvolvida nos anos 1960, já no IF, tem incontestável influência da cultura que Gerard Hepp conseguiu implantar no CPF [3]. Como jovens recém-formados e claramente orientados para a Física Teórica, Gerhard e Darcy tiveram pouco contato de cunho acadêmico com

\footnotetext{
$8 \mathrm{Na}$ verdade, naquela época o que existia era o Departamento de Física da Filosofia, que em 1969 viria a se transformar no que hoje é o Instituto de Física da USP.
}

Hepp, que era engenheiro eletrônico da Philips, perito em detetores nucleares. Podemos dizer que na transição CPF-IF eles viviam em mundos paralelos. Talvez isso seja parte da explicação para a existência dessas duas cartas.

Em sua carta para Salmeron, Hepp descreve o CPF e o convida para trabalhar no Centro, mas não explicita em que condição funcional (ver cópia dessa carta na Figura S2). Menciona o projeto da construção de um prédio no morro Sant'Ana para a instalação do CPF. O projeto existiu, mas jamais foi executado. Ele destaca alguns equipamentos desenvolvidos no Centro e diz que estão "iniciando a construção de um pequeno acelerador Cockroft-Walton". Ao finalizar a carta, Hepp convida Salmeron para o vir trabalhar no CPF: "Desta maneira, gostaria muito de obter a colaboração; não seria trabalho fácil. Precisa-se de mentalidade de pioneiro. Assim, desejamos saber se está disposto a considerar essa possibilidade ou se não nos resta nenhuma esperança nesse sentido."

Em uma lauda, não há relato mais preciso do que era o CPF naquele ano que seria o último de sua existência. Aos interessados em outros detalhes, sugiro a leitura de $[1$, p. 20,3$]$.

Da mesma forma que a carta de Hepp delineia de forma primorosa o cenário do $\mathrm{CPF}$, a carta de Salmeron (Figure S1) delineia o cenário da Física Experimental no Brasil no final dos anos 1950. Infelizmente ele não pôde aceitar o convite porque tinha planos para permanecer no CERN por mais alguns anos.

Examinando em retrospectiva as duas primeiras décadas do IF, ficamos em dúvida se foram as sugestões de Salmeram que pavimentaram os procedimentos administrativos da pesquisa no IF, ou se foi uma simples coincidência de modos de pensar o fazer científico em uma instituição emergente entre Salmeron, Gerhard e Darcy. Mas, é curioso que a importância da carta de Salmeron não tenha ficado registrada nas memórias de Gerhard e Darcy. Em suas memórias, Gerhard diz a propósito da primeira vez em que encontrou-se com Salmeron em Genebra, que só o conhecia "através de troca de correspondência entre ele e Darcy e eu sobre o início de pesquisa em Física no Instituto". Não faz qualquer comentário a respeito da importância das recomendações de Salmeron.

Em sua carta, com 5 laudas datilografadas, Salmeron não menciona a carta recebida de Hepp. Ele menciona Hepp para se referir ao CBPF. Todavia o conteúdo da carta sugere que ele leu com atenção a carta de Hepp, por ele considerado como profissional de alta competência.

Aparentemente a ideia da construção de um acelerador de partículas, fervorosamente defendida por Hepp, era compartilhada por Gerhard e Darcy, se não por convicção, pelo menos por respeito a Hepp. De acordo com Salmeron, Gerhard e Darcy haviam mencionada em uma das cartas o interesse na compra de um acelerador, e que o prof. Saraiva haveria dito que seria um Van de Graaff ou um 
Cockroft-Walton, o acelerador mencionado por Hepp em sua carta para Salmeron. De acordo com os registros nas Atas do Conselho Técnico Científico do CPF-URGS [3], em reunião de 5/11/53, Hepp sugere que o CPF adquira um acelerador. No orçamento para 1954, Hepp consegue Cr\$250.000,00 para a construção de um acelerador. Naquele mesmo ano, as obras do sincrocíclotron do CNPq foram paralisadas no Rio de Janeiro [3]. Em 1956 o CD do CNPq discute o destino do acelerador, tendo a URGS como candidata para receber a máquina. Chegaram a um impasse [5]. Sabia-se que José Goldemberg e Hervásio de Carvalho se opunham à vinda do equipamento para o Sul. No entanto em mensagem eletrônica para o autor, em 17/2/2010, o prof. Goldemberg diz que não lembra desse fato. Diz que "na época eu era um assistente jovem e não tinha qualquer ligação com o CNPq de modo que nem haveria razão para ser consultado". Todavia, conforme Ana Maria Ribeiro de Andrade, Goldemberg participou de uma comissão do CNPq, em 1964, para decidir o destino da máquina [6]. De qualquer modo, o CNPq não atendeu ao pedido do Reitor da URGS para instalar o acelerador no CPF. No orçamento de 1957, foram reservados $\mathrm{Cr} \$ 500.000,00$ para o acelerador. Em reunião do CTC-CPF em 26/3/58, Hepp informa que a Divisão de Eletrônica está "preparando um pequeno acelerador, mas vai devagar porque toda a elaboração depende do alto vácuo". Essa informação consta na carta que ele enviou a Salmeron.

Em 23/9/1958, o CNPq firma convênio com a URGS para que uma equipe do CPF, liderada por Hepp, desloquese para o Rio de Janeiro para remontar o sincrocíclotron [3]. Eles conseguiram montar o acelerador e fazê-lo funcionar, mas intervenções político-militares impediram que ele fosse usado a contento. Decepcionado, Hepp retorna ao seu posto na Phillips, na Holanda, em 1963. A ideia de se construir um acelerador no CPF arrefeceu, pela falta de seu defensor, e a essa altura as pesquisas em Física Nuclear Teórica, sob a liderança de Maris já encontravam-se a todo vapor.

Apesar de todo esse esforço da URGS, por meio do $\mathrm{CPF}$, as recomendações de Salmeron não tiveram prosseguimento porque no ano seguinte Gerhard e Darcy conheceram Maris, que definiu toda a estratégia de pesquisa no IF-UFRGS. É provável que essa circunstância tenha provocado o "esquecimento" da relevância da carta de Salmeron nas memórias de Gerhard e Darcy.

\section{O professor-gestor: criação do IF}

Logo após a volta de Gerhard, em março de 1959, de seu breve estágio em Heidelberg, o Centro de Pesquisas Físicas da URGS (CPF-URGS) [3] foi extinto, e criado o Instituto de Física pela portaria 117, de 9 de março de 1959. Portanto, antes de passar de aprendiz de cientista a cientista profissional, Gerhard teve que atuar como gestor, o mesmo acontecendo com seu companheiro de aventura acadêmica, Darcy Dillenburg. De acordo com a portaria 117, de 9 de março de 1959:

Toda a infraestrutura do CPF-URGS, incluindo o acervo bibliográfico e o espaço físico, foi transferida para o IF-URGS (atualmente, IF-UFRGS). O pessoal do CPF-URGS foi relotado no novo órgão. A organização administrativa e científica do CPF-URGS foi basicamente preservada, constituindo-se em Direção, Conselho Técnico Científico e Conselho Deliberativo. As atividades acadêmicas do Instituto se realizavam no âmbito das seguintes Divisões: Física Teórica; Eletrônica; Radioquímica; Ensino [1, p. 30].

Na data da sua criação, não havia catedrático entre os professores do IF, razão pela qual foi nomeado diretor o prof. Saviniano de Castro Marques, catedrático do Instituto de Química da Escola de Engenharia, que se mostrou excelente administrador, deixando para os jovens candidatos a cientista a tarefa da gestão acadêmica. Essa tarefa inicial coube a Gerhard e Darcy, e eles contaram com algum golpe de sorte. Entre abril e maio de 1959, Darcy ausentou-se para um estágio na Cidade do México com Marcos Moshinsky, onde ficou sabendo que ali se realizaria, em julho, a primeira Escola Latino-Americana de Física (ELAF), organizada por Moshinsky. Conseguiu que este convidasse Gerhard para participar do evento, com passagem e bolsa. Gerhard considera que esta foi a terceira oportunidade que ele teve para aprender Física e entrar na pesquisa. Voltarei a esse assunto mais adiante. Tratarei aqui da oportunidade que os dois jovens gestores tiveram para dar um salto de qualidade nos projetos de pesquisa do IF.

Durante a ELAF, Gerhard e Darcy tornavam público que estavam à procura de um físico nuclear teórico para trabalhar no IF. Participando do evento, o físico Mael A. Melvin, da Universidade Estadual da Flórida, em Tallahassee, informou que em sua universidade estava sendo instalado um novo acelerador (Tandem Van de Graaff), o que estava causando uma "grande perturbação" no departamento. Por essa razão, ele e um seu colega alemão, físico nuclear teórico mais moço, estavam pensando em se afastar por um ano, e considerando inclusive passar esse ano na América do Sul. Portanto, ele poderia vir para Porto Alegre, mas acabou indo para Bariloche (Argentina).

O jovem físico alemão era Theodor August Johannes Maris, que era físico nuclear teórico, ao contrário de Melvin, que era mais físico de materiais. Portanto, Maris era mais interessante do que Melvin para os planos de Gerhard e Darcy, que imediatamente começaram a tomar as providências administrativas, após uma breve troca de informações com Maris. Os recursos financeiros foram obtidos junto à $\mathrm{OEA}$, ao $\mathrm{CNPq}$ e naturalmente à Universidade, totalizando um salário superior ao do próprio Reitor. Tudo isso gerou os primeiros obstácu- 
los administrativos a serem enfrentados por Gerhard e Darcy.

O financiamento de três fontes era não ortodoxo. Para superar isso tiveram que contar com a confiança quase inabalável que Maris tinha na humanidade. Para usar uma expressão popular, ele confiava muito mais na palavra empenhada do que em documentos assinados. Se não fosse essa confiança, Maris não aceitaria esse contrato "diferente". Com a aceitação de Maris, os jovens gestores tiveram que enfrentar as regras burocráticas da Universidade. A primeira foi a oposição de um Assessor Jurídico que alegava inconstitucionalidade desse tipo de contrato. A despeito dessa recomendação, o Reitor autorizou a contratação de Maris. A chegada de Maris a Porto Alegre, na noite de 4 de outubro de 1959, com a esposa e duas filhas adolescentes, está bem relatada em [7], onde consta a informação de que já no dia seguinte estava ele no Instituto, tomando seu primeiro contato com as atividades que iria desenvolver. A seguir apresentarei os eventos administrativos conduzidos por Gerhard e Darcy logo após a chegada de Maris. Os eventos científicos serão apresentados na próxima seção.

Dois temas de pesquisa poderiam ser a semente da história do IF-UFRGS. Um deles seria na área de Física de Nêutrons, que Darcy estava desenvolvendo para sua tese de cátedra. O outro, que terminou prevalecendo, era sobre reações quase-livres de prótons, no qual Maris vinha trabalhando na Escandinávia e nos EUA, como veremos na próxima seção.

Para assentar as ideias e ver como o projeto do IFUFRGS poderia ser inserido no universo científico brasileiro, decidiram organizar um pequeno simpósio com a participação de pesquisadores de São Paulo (Ewa Wanda Cybulska, José Goldemberg e Oscar Sala) e do Rio de Janeiro (Luiz Carlos Gomes e Cesar Lattes). Também participou Mael Melvin, amigo de Maris e que estava na Argentina. O evento realizou-se de 7 a 12 de dezembro de 1959, dois meses após a chegada de Maris. Desses convidados, Cesar Lattes era o mais ilustre e o principal inspirador da criação do CPF-URGS, razão pela qual foi levado à presença do reitor Paglioli. A Fig. 3 registra o momento da reunião. Relatório de Gerhard sobre este simpósio encontra-se em [1, p. 393].

Ao longo dos seus três primeiros anos o IF enfrentou uma série de dificuldades, as quais exigiram muita dedicação de Gerhard e Darcy, em seus primeiros dias como gestores. Maris praticamente não se envolvia com atividades de administração. Esteve sempre concentrado em sua pesquisa e na orientação de seus estudantes de pós-graduação. Em suas reminiscências, não publicadas, Gerhard destaca três problemas administrativos: (1) falta de verbas para pessoal, material de consumo e investimentos; (2) recrutamento e contratação de egressos do curso de Física e (3) política de qualidade acadêmica.

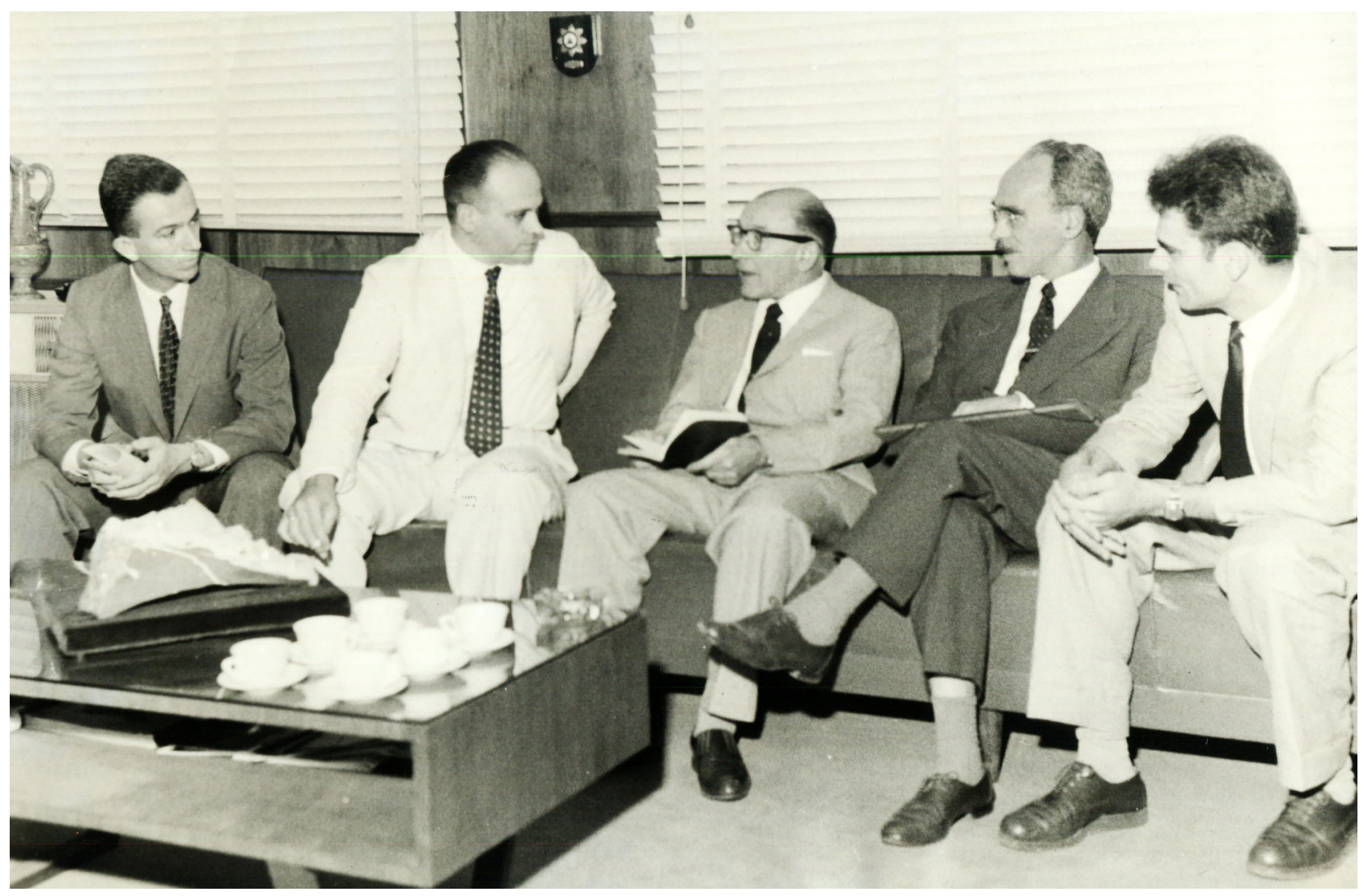

Figura 3: A partir da esquerda: Darcy Dillenburg, Cesare Mansueto Giulio Lattes, Elyseu Paglioli (Reitor da UFRGS), Saviniano de Castro Marques (Diretor do IF) e Gerhard Jacob. Dezembro de 1959. Foto do acervo do IF-UFRGS. 
Sobre esse último problema, Gerhard relata em suas reminiscências:

O terceiro problema, apesar de relativamente pequeno, revestiu-se de importância por envolver política de qualidade acadêmica: antes de enviar trabalhos para publicação, eles deveriam ser analisados quanto ao mérito por uma comissão de pesquisadores mais experientes. Isso causou insatisfação entre alguns membros do Instituto (inclusive resultando na saída de um colega muito competente). Entretanto, estou convencido de que evitar a remessa de trabalhos não adequados para publicação, contribuiu para dar ao Instituto uma reputação de seriedade entre os editores das melhores revistas.

Gerhard praticamente abandonou sua carreira científica em 1976, quando foi convidado pelo reitor Homero Só Jobim para ocupar a Pró-Reitoria de Pesquisa e PósGraduação (PRPPG) 9 Foi o primeiro docente do IF a integrar o escalão superior da Universidade, e exerceu sua função seguindo a orientação simples e direta do reitor ${ }^{10}$. "Organizar a Pró-Reitoria como eu achasse, mas com uma finalidade principal: Simplificar a vida dos pesquisadores, tornando mais ágil a burocracia indispensável e eliminar aquela que não o fosse."

É de se imaginar as dificuldades de gestão da pesquisa e pós-graduação em uma universidade com pouca tradição de pesquisa em várias áreas do conhecimento, sobretudo nas ciências humanas. Mas também havia problemas de gestão nas áreas onde a pesquisa já se encontrava em boa fase de desenvolvimento, como a burocracia na gestão dos recursos da FINEP. Foi em sua gestão na PRPPG que o processo foi desburocratizado.

$\mathrm{Na}$ mencionada entrevista que me concedeu em 2015, Gerhard disse que logo percebeu que como Pró-Reitor não tinha condições de trabalhar em Física. Decidiu abandonar a pesquisa porque entendia que poderia fazer mais pela pesquisa na Universidade como gestor do que o faria no IF. "E o novo trabalho deu-me muita satisfação e compensações. Também fiquei muito contente por minha saída do Instituto de Física não ter causado problema algum: a instituição já estava suficientemente madura para não mais depender de pessoas, a estrutura já absorvia perdas", concluiu.

Earle Diniz Macarthy Moreira assume a reitoria ao final do mandato de Jobim e mantém Gerhard na PRPPG, mas na metade do mandato, quando Francisco L. dos S. Ferraz, Pró-Reitor de Planejamento e de Administração é convidado para assumir uma função na Secretaria de Educação Superior (SESu) do MEC, Macarthy solicitou que Gerhard assumisse a Pró-Reitoria de Planejamento (PRP), ficando Edmundo Kanan Marques na PRPPG. Foi durante as gestões de Ferraz e Gerhard na PRP que

\footnotetext{
9 Foi na gestão de Jobim que todas as Pró-Reitorias foram criadas. 10 Entrevista ao autor, em 21.3.2015.
}

o campus do Vale foi construído. O IF saiu do campus Central para o campus do Vale em 1985.

Durante aqueles anos na administração central, Gerhard passou de admirador das habilidades político-administrativas de Ferraz, para seu fiel amigo e Vice-Reitor. Em 1988 ele o sucedeu no cargo de Reitor. Permaneceu no cargo menos de dois anos, pois em 1990 foi nomeado presidente do CNPq, por indicação de José Goldemberg, então Secretário de Ciência e Tecnologia do governo Collor. Gerhard permaneceu um ano nesse cargo. A saída de Gerhard da reitoria da UFRGS para a presidência do $\mathrm{CNPq}$ foi muito traumática para a comunidade universitária, e teve como consequência dolorosa, anos depois, a rejeição de sua indicação como Professor Emérito da UFRGS.

Desde 1965, um ano após sua defesa de Cátedra, Gerhard sempre teve intensa participação na gestão do CNPq, iniciando como membro do Conselho Deliberativo (CD-CNPq) para o período 1965-1971. Depois é nomeado para o mesmo cargo no período 1986-1989. Portanto para além da amizade de longa data com Goldemberg, o convite para a presidência do $\mathrm{CNPq}$ fazia jus à sua reconhecida competência como gestor acadêmico. Seria tudo ótimo, não fosse o mal-estar causado na comunidade acadêmica da UFRGS.

Durante o primeiro mandato no CD, Gerhard teve como colegas físicos: Goldemberg, Oscar Sala, Sérgio Mascarenhas, Erasmo Madureira Ferreira, Sérgio Machado Rezende, Ramayana Gazzinelli e Humberto Siqueira Brandi. Foi uma época muito produtiva do gestor Gerhard, apesar de alguns percalços, como as cassações de vários professores universitários em 1969, alguns deles renomados cientistas: Alberto de Carvalho e Silva, Hélio Lourenço, João Christóvão Cardoso, Bolivar Lamounier, Jaime Tiomno com sua esposa Elisa Frota Pessoa, Florestan Fernandes, José Leite Lopes com sua esposa Maria Laura Mouzinho Leite Lopes, Elza Berquó, Fernando Henrique Cardoso, Isaías Raw, José Arthur Gianotti, Luiz Hildebrando Pereira da Silva e Mário Schenberg, entre outros. O CD solicitou que o Presidente do CNPq, Antônio Moreira Couceiro, falasse pessoalmente com o Presidente da República, Costa e Silva, para tentar reverter a situação. Como se sabia naquela época, não havia volta em decisão tomada nessa área.

Durante o primeiro mandato de Gerhard no CD, ele e Sérgio Mascarenhas foram decisivos na viabilização de um auxílio institucional do CNPq para a ida de Sérgio Rezende para a UFPE, junto com recém-doutores e doutorandos (Cid Bartolomeu de Araújo, José Roberto Rios Leite, Maurício Domingues Coutinho Filho, entre outros). É importante destacar que esse foi um dos primeiros auxílios institucionais, pois o $\mathrm{CNPq}$ praticamente só concedia auxílios individuais.

Ao final do seu mandato, em 1971, Gerhard foi substituído por Jorge André Swieca.

Em 1986, no mandato de Crodowaldo Pavan como Presidente do CNPq (1986-1990), Gerhard é novamente 
nomeado para o CD, para o período 1986-1989. Logo se deparou com um problema delicado, a concessão de auxílios/bolsa administrativamente para atender a pedidos específicos, sobretudo de políticos. Tratava-se de uma concessão fora dos critérios acadêmicos para conseguir boa vontade na concessão das verbas. Em discussão do CD com Pavan ficou acertado que uma pequena percentagem dos recursos poderia ser utilizada a critério do Presidente, sem parecer dos Comitês Assessores (CA).

Esse período, que culminou com a curta permanência de Gerhard na Reitoria da UFRGS e na presidência do CNPq, define um turbulento contexto político e acadêmico de tal extensão e complexidade que merece uma análise historiográfica além do escopo do presente trabalho.

Depois da traumática experiência na presidência do CNPq, Gerhard decidiu não mais assumir cargo público algum. Mas, o DNA do gestor acadêmico jamais deixou de correr em suas veias. Entre 1991 e 2002 Gerhard envolveu-se em várias atividades de consultoria, entre os quais, membro do Conselho Superior da Fapergs, tendo ocupado a presidência no período 1997-2000. Durante muito tempo foi o representante brasileiro na coordenação do acordo de cooperação com o DAAD. Esteve envolvido no planejamento e criação do Centro de Excelência em Tecnologias Avançadas (CETA), no RS.

Em dezembro de 2002 aceita convite de Nelson Boeira, que a partir de janeiro de 2003 seria nomeado Reitor da Universidade Estadual do Rio Grande do Sul (UERGS), para assumir a Pró-Reitoria de Pesquisa e Pós-Graduação. Gerhard permaneceu na UERGS até 2006. Foi seu último cargo como executivo universitário.

\section{6. $\mathrm{O}$ cientista}

Excetuando alguns momentos em que esteve em missão de estudo e trabalho no exterior, jamais as atividades do cientista Gerhard estiveram dissociadas das atividades administrativas. Isso também é verdade para seu parceiro de criação do IF-UFRGS, Darcy Dillenburg. Por causa do seu intenso envolvimento com atividades administrativas, quantitativamente a produção científica de Gerhard (15 trabalhos) pode ser considerada muito pequena (menos de um artigo por ano) e toda sua vida cientifica durou apenas 18 anos. E só co-orientou 4 dissertações e 2 teses. Todavia, como veremos adiante alguns dos seus trabalhos tiveram grande repercussão.

Tanto Gerhard, quanto Darcy, não incluíram em suas listas de publicação os trabalhos publicados enquanto faziam a especialização no IF-USP. Consideravam que tinham participação irrelevante. Portanto, o primeiro trabalho de Gerhard é também o primeiro trabalho do IF-UFRGS [4]. Esse trabalho já foi mencionado. Tratavase de um trabalho sobre transições quânticas em núcleos isoméricos, tema do interesse de Eichler e pouco atinente à linha de pesquisa que Gerhard desenvolveu sob orientação de Maris. O último trabalho de física publicado por
Gerhard resultou da dissertação de mestrado de Paulo Machado Mors, que ele co-orientou com Victoria Elnecave Herscovitz [8].

A linha de pesquisa em espalhamento nuclear ou espalhamento ( $\mathrm{p}, 2 \mathrm{p})$ como ficou popularmente conhecido, tem a ver com o modelo de camadas, cujos primeiros resultados experimentais foram obtidos em Uppsala, Harwell e Chicago [9]. O primeiro artigo de Gerhard pertinente ao tema, publicado na época que Gerhard estava no México para participar da I ELAF (sobre a ELAF, ver comentário no início do artigo) trata de um cálculo dos elementos de matriz para o modelo de camadas no núcleo [10], cujo detalhamento está fora do escopo do presente artigo.

O primeiro artigo de Gerhard tratando especificamente do espalhamento (p, 2p) foi publicado em 1960, em parceria com seu orientador, Maris [11]. Trata-se de um texto extremamente claro e didático, uma característica dos trabalhos de Gerhard. É possível ter uma boa ideia dessa linha de pesquisa, mesmo não tendo conhecimento formal pertinente, lendo esse artigo e um outro que eles publicaram em 1966, na Reviews of Modern Physics . [12]. A propósito, esse artigo da RMP foi, no período 1973-1978, o artigo de Física do Terceiro Mundo mais citado no Primeiro Mundo [2]. Para leitores com formação em Física Nuclear sugiro a leitura de artigos mais específicos [13-15].

Não é objetivo aqui tratar o espalhamento (p, 2p) do ponto de vista rigorosamente formal. $\mathrm{O}$ que se pretende aqui é abordá-lo sob a ótica pedagógica, por meio de um esboço de uma transposição didática apropriada para disciplinas que tratam da Física Moderna, quer seja na graduação ou no ensino médio. Obviamente que uma transposição didática requer a simplificação da manipulação conceitual. Para uma leitura complementar nesse nível de abordagem histórico-pedagógica, com um conteúdo mais aprofundado, sugiro [16,17].

\section{O modelo de camadas e o espalhamento $(\mathbf{p}, 2 \mathrm{p})$}

Embora não seja objetivo deste trabalho tratar outro assunto que não seja aquele no qual Gerhard trabalhou, acho instrutivo abordar, do ponto de vista histórico, o desenvolvimento do modelo de camadas desde Walter Maurice Elsasser [18-21] até Maria Goeppert-Mayer [22] e Johannes Hans Daniel Jensen ${ }^{11}$ [23]. Por esses trabalhos, Goeppert-Mayer e Jensen dividiram o Nobel de Física de 1963 com Eugene Wigner.

Uma boa ideia do cenário nos anos 1940 foi dada na apresentação dos laureados, quando o professor Ivar Waller, membro do Comitê Nobel para a Física, afirmou ${ }^{12}$,

\footnotetext{
11 Foi Jensen quem acolheu Gerhard em Heidelberg, logo depois da Segunda Conferência Internacional das Nações Unidas para Usos Pacíficos da Energia Nuclear, que se realizaria em Genebra, em setembro de 1958, conforme descrito anteriormente.

12 https://www.nobelprize.org/prizes/physics/1963/ceremony-speech/
} 
Verificou-se durante a década de 1920 e, em particular, na década de 1930 que prótons e nêutrons formam sistemas particularmente estáveis em um núcleo atômico, quando o número de um ou outro tipo de nucleon é um dos chamados números mágicos 2, 8, 20, 28, 50, 82 e 126. Vários físicos, em particular Elsasser, tentaram interpretar os números mágicos em analogia à explicação bem-sucedida de Niels Bohr do sistema periódico dos elementos. Foi então assumido que os nucleons se movem em órbitas em um campo de força esférico e que essas órbitas estão dispostas em camadas que são energeticamente bem separadas. Os números mágicos devem corresponder a camadas completas. Essa interpretação foi bemsucedida apenas para núcleos leves. Contudo, não foi possível explicar mais do que os três primeiros números mágicos e por muitos anos outro modelo dominoy ${ }^{13}$ (Tradução nossa).

O modelo de camadas para o núcleo foi desenvolvido ao longo dos anos 1930, por Walter Maurice Elsasser [18-20], a partir de uma proposta apresentada por James H. Bartlett em direta analogia com a estrutura eletrônica do modelo de Bohr [24]. No entanto, como afirma Kragh [25], naquela década o modelo não tinha uma boa justificativa teórica, os resultados experimentais eram escassos, e o modelo não conseguia produzir a camada fechada para núcleos com 82 e 126 nêutrons. Além disso, ele contradizia as ideias de Bohr sobre o núcleo, principalmente o modelo da gota líquida, proposto por Gamow [26] e desenvolvido por Niels Bohr e John Archibald Wheeler [27]. Em 1936, o modelo de camadas foi duramente criticado por Niels Bohr [28] e a partir de então foi negligenciado pelos físicos mais importantes da época. Quase todos trabalhavam com o modelo da gota líquida. O próprio Elsasser passou a dedicar-se ao geomagnetismo, área em que ficou famoso, sendo considerado um dos pais da teoria do dinâmo, atualmente aceita como explicação do magnetismo terrestre [29].

O modelo começou a renascer, disse Maria GoeppertMayer em sua conferência Nobel [22], quando ela e Edward Teller estavam trabalhando em um artigo sobre a origem dos elementos e "tropeçaram nos números mágicos" [30]. Foi só então que Goeppert-Mayer começou a ler os artigo de Elsasser [18-20]. Perceberam que alguns núcleos eram mais abundantes, tanto no que se refere à sua distribuição isotópica, quanto à sua existência na natureza, e também eram mais estáveis que os outros. Esses núcleos possuíam determinados números de prótons ou nêutrons, que passaram a ser denominados números mágicos: 2, 8, 20, 28, 50, 82, 126.

Uma analogia muito importante entre o modelo de camadas e o modelo de Bohr, refere-se à energia de ligação do elétron no átomo (modelo de Bohr) ou de um núcleon

13 Provavelmente, Waller refere-se ao modelo da gota líquida. (próton ou nêutron) no núcleo (modelo de camadas). A energia de ligação do elétron é medida pelo potencial de ionização ou energia de ionização, cujos valores para os 100 primeiros elementos da tabela periódica estão plotados na Fig. 4. Observe que a energia cresce em cada período da tabela, atingindo seu valor máximo no gás nobre do período. Então, por exemplo, extrair o elétron mais externo de um átomo de hélio é muito mais difícil que extrair o elétron mais externo do átomo de lítio. Observe que os gases nobres têm suas últimas camadas cheias, de modo que se gasta muita energia para extrair um elétron de uma camada cheia.

No caso do núcleo, aqueles cujo número de prótons ou neutros é igual a um número mágico são análogos aos gases nobres. São os núcleos de camada cheia, como ficaram conhecidos na literatura.

Na mesma época que Goeppert-Mayer e Jensen trabalhavam no desenvolvimento do modelo de camadas, alguns pesquisadores começavam a investir em estudos teóricos e experimentais sobre o espalhamento de prótons e nêutrons por diversos núcleos [31-33]. Do ponto de vista teórico, talvez o trabalho mais inspirador para a linha de pesquisa que viria a ser seguida por Maris em Uppsala e depois adotada no IF-UFRGS tenha sido aquele publicado em 1947 por Robert Serber [33]. Maris refere-se a esse trabalho de Serber no artigo em que ele e colaboradores apresentam as possibilidades de medidas de espalhamento $(\mathrm{p}, 2 \mathrm{p})$ para a investigação da estrutura de camadas [34]. Esse trabalho e aquele no qual Gerhard apresenta seus primeiros cálculos sob orientação de Maris [11], são bastante instrutivos para quem deseja ter uma ideia inicial do assunto.

O problema básico é o bombardeamento de um núcleo, $\mathrm{N}$, com $\mathrm{Z}$ prótons e número de massa (prótons + nêutrons) $\mathrm{A}$, por um próton, p. O núcleo resultante terá um próton a menos e, portanto, número de massa A-1. Além do núcleo, que ficará em repouso, dois prótons serão espalhados. Portanto, a equação que descreve esta reação é:

$$
p_{1}^{1}+N_{Z}^{A} \rightarrow 2 p_{1}^{1}+N_{Z-1}^{A-1},
$$

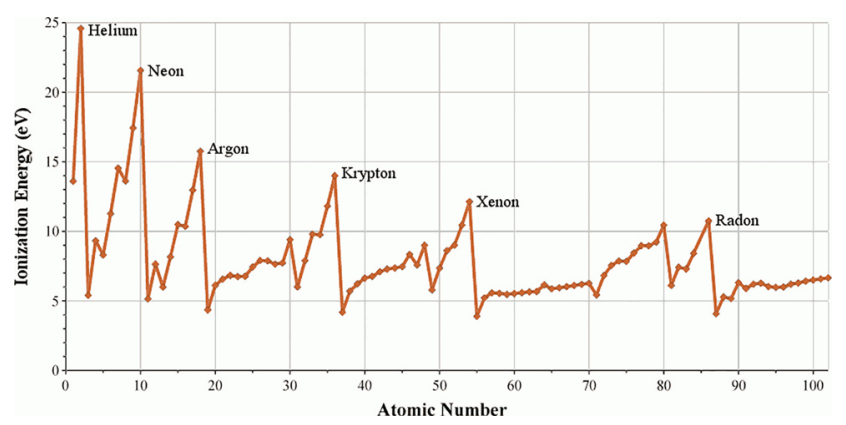

Figura 4: Energia de ionização dos 100 primeiros elementos da tabela periódica. Disponível em $<$ https://upload.wikimedia.org/wikipedia/commons/2/ 26/Ionization_energies_2.png >. Acesso em 15/11/2019. 
sinteticamente representada pela expressão:

$$
N_{Z}^{A}(p, 2 p) N_{Z-1}^{A-1} \text {. }
$$

Nas condições experimentais de então, o experimento típico era assim: um nucleon (próton ou nêutron) é lançado com uma certa energia ( $50 \mathrm{MeV}$ a $500 \mathrm{Mev}$ ) sobre um núcleo. O choque resulta na saída de dois nucleons, ficando o núcleo com um nucleon a menos. A condição para a existência dessa reação é que não haja qualquer interação do nucleon incidente, nem dos dois emergentes, com o núcleo. Essa exigência só faz sentido estritamente no caso do modelo de partículas independentes, ou seja no modelo da camadas. No caso de um núcleo real, onde os nucleons interagem entre si, a remoção de um nucleon influencia fortemente todas as partículas do núcleo.

O espalhamento quasi-livre ( $p, 2 \mathrm{p})$ lembra o efeito Compton [35], onde o feixe de raios-X é substituído por um feixe de prótons, e o elétron espalhado é substituído por um próton (Fig. 5). Essa analogia é apenas intuitiva e não corresponde exatamente ao espalhamento Compton nuclear, descoberto no final dos anos 1940 e início dos 1950 [36]. Menciono esse fato apenas como registro histórico. Sua discussão está fora do escopo do presente artigo.

Sobre o espalhamento quasi-livre, Gerhard publicou 10 artigos [8,9,11-15,37-39]. Desses, o que causou mais impacto internacional foi aquele publicado na Reviews of Modern Physics (RMP) [12], baseado na tese de Cátedra de Gerhard, defendida em 1964. Para os interessados nos aspectos históricos desse tema, cabe registrar que a primeira referência citada por Gerhard e Maris nesse artigo, é um livro publicado em 1955, por Goeppert-Mayer e Jensen ${ }^{14}$ Acho conveniente encerrar esta seção apresen-

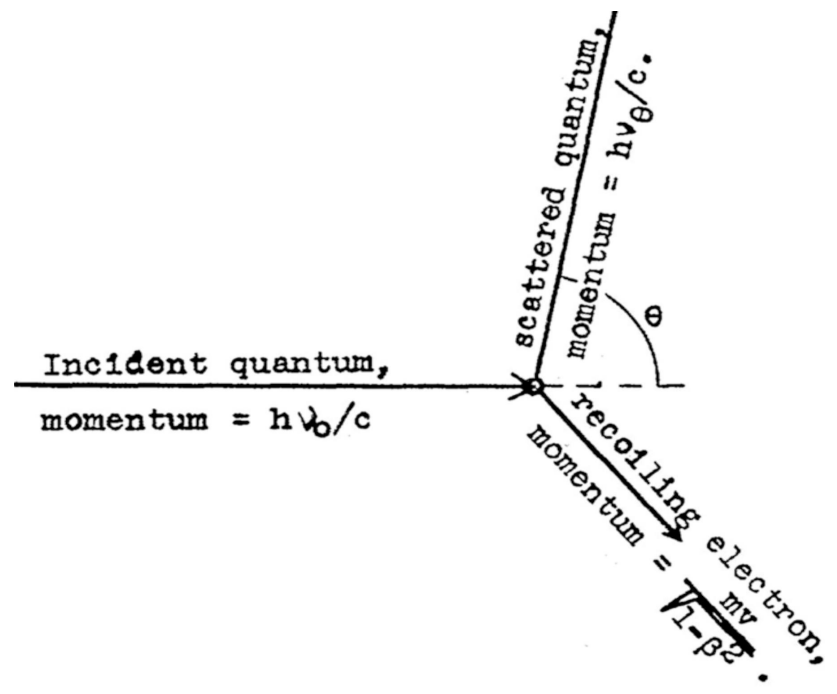

Figura 5: Ilustração do espalhamento de um feixe de raios- $X$ por um elétron quase livre. $O$ feixe incidente perde energia que é cedida ao elétron espalhado. Esse foi um dos primeiros experimentos a mostrar o caráter corpuscular do fóton. Figura disponível em [35].

14 M. G. Mayer and J. H. D. Jensen, Elementary Theory of Nuclear Shell Structure (John Wiley \& Sons, Inc., New York, 1955). tando extratos desse artigo, que considero extremamente didático e instrutivo para um resumo geral da área de pesquisa que ocupou grande parte da vida científica de Gerhard.

Nos últimos quinze anos, o modelo de camadas tem sido bem sucedido na explicação de inúmeras propriedades do núcleo. Com relação ao domínio de validade do modelo, devese, no entanto, observar que embora a existência de camadas fortemente ligadas parece estar implícito, quase todos os experimentos realizados até recentemente foram restritos a investigações das camadas menos ligadas e das lacunas nas camadas. (...)

Experimentos que são particularmente adequados para investigar a estrutura interna das camadas nucleares são os experimentos quaselivres (também chamados de quase-elásticos). Qualitativamente, espalhamento quase-livre significa que uma partícula de alta energia (100-1000 MeV) extrai um nucleon de um núcleo sem que ocorra qualquer interação violenta entre o núcleo e a partícula incidente ou entre o núcleo e as partículas emergentes. Pelo fato do livre caminho médio de nucleons de alta energia na matéria nuclear ser da mesma ordem de grandeza do raio nuclear, tais eventos são consideravelmente prováveis (...)

Os primeiros experimentos demonstrando a existência de tais processos foram realizados em Berkeley, em 1952, através do bombardeamento de núcleos leves com prótons de 340 $\mathrm{MeV}$. Os prótons emergentes foram observados por meio de correlação angular [31]. Esses eventos podem ser descritos assumindo que o próton incidente colide com um único próton no núcleo, como se ambos fossem partículas $\operatorname{livres}(\ldots)$

Até recentemente somente experimentos com prótons foram considerados. Em princípio, o longo livre caminho médio dos elétrons na matéria nuclear faz dessa partícula projétil preferencial. Embora esses experimentos sejam difíceis, a estrutura de camadas do C-12 e do $\mathrm{Al}-27$ foram recentemente investigadas no Istituto Superiore di Sanità, em Frascati; espalhamento quasi-livre elétron-próton em H-2, H-3, e He-3 foram realizados em Stanford e Orsay. Em todos esses experimentos os elétrons incidentes tinham energias entre $500 \mathrm{MeV}$ e $600 \mathrm{MeV}$. (Tradução nossa).

A ilustração do experimento, apresentada por Gerhard e Maris no artigo da RMP (Fig. 6) é praticamente idêntica àquela apresentada por Compton (Fig. 6). Basta 


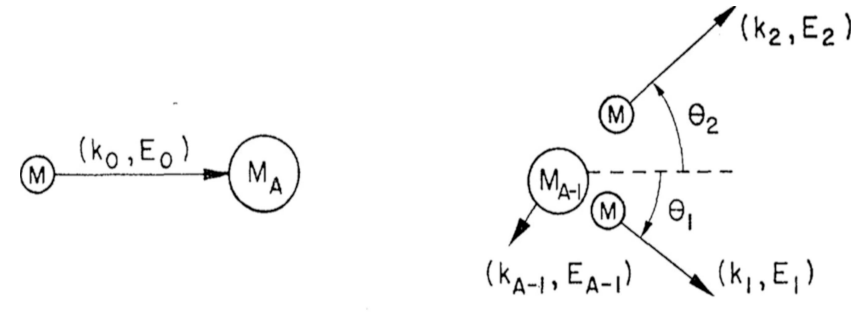

Initial state

Final state

Figura 6: Ilustração do espalhamento $(p, 2 p)$. Disponível em [12].

substituir o feixe de raios-X (Compton) por um feixe de prótons, $\mathrm{M}$, e o átomo por um núcleo, $\mathrm{M}_{\mathrm{A}}$. Na saída, o experimento $(\mathrm{p}, 2 \mathrm{p})$ resulta em dois prótons, $\mathrm{M}$, enquanto no experimento de Compton tem-se um elétron e um raio-X.

Conforme já mencionado, o espalhamento quase-livre mostrou-se uma ferramenta útil para a investigação do modelo nuclear de camadas. Em aproximadamente quinze anos de trabalho teórico e experimental com esse tipo de experimento, diversos pesquisadores apresentaram considerável avanço no conhecimento da estrutura nuclear.

O estado da arte da área em meados dos anos 1970 é apresentado em um segundo artigo publicado por Gerhard e Maris na RMP, em 1973, complementando aquele de 1966 [37]. Depois dos anos 1970, os estudos evoluíram no aperfeiçoamento dos métodos computacionais a partir da inclusão de mais propriedades atômicas, tais como o efeito da polarização do spin e a interação spin-órbita $[15,39]$, assim como no uso de outras partículas, tais como elétrons, nêutrons, dêuterons e partículas alfa.

Para concluir o relato dos trabalhos desenvolvidos no IF-UFRGS até o final dos anos 1970, apresentarei os principais resultados obtidos, todos válidos para espalhamentos (p, 2p) e (e,e'p), para núcleos com $\mathrm{A}>4$, prótons incidentes com energia maior do que $150 \mathrm{MeV}$ e elétrons incidentes com energia maior do que $300 \mathrm{MeV}$. Além dessas limitações nas condições experimentais, para se chegar a resultados teóricos que explicassem satisfatoriamente resultados experimentais, vários métodos computacionais tiveram que ser desenvolvidos para levar em conta as propriedades quânticas dos nucleons. Por exemplo, os primeiros estudos do espalhamento (p, 2p) partem de um modelo muito simplificado. Um próton livre atinge outro próton quasi-livre no interior de um núcleo, sem que nem um, nem outro interaja com o restante do núcleo. Obviamente, sendo o próton (e o elétron) uma partícula dotada de carga elétrica e de spin, deve-se levar em consideração as interações eletromagnéticas entre eles, como a interação entre o spin de um próton e o momento angular gerado pelo seu movimento orbital. Essa última é conhecida tecnicamente como interação spin-órbita, que depende do estado de polarização dos prótons. Esse foi um dos problemas enfrentados nos anos 1970 por Gerhard e colaboradores $[15,39]$.

Já no artigo da RMP de 1966, Gerhard e Maris perceberam que a correlação angular dos pares de prótons emergentes era consideravelmente diferente daquela observada nos experimentos. Isso era consequência do fato de que os prótons não estavam em repouso no núcleo. Eles apresentavam uma distribuição de momentos lineares, assim como uma distribuição de energia. Isso permitiu que eles obtivessem os níveis de energia das camadas nucleares. Ou seja, para uma dada energia do próton incidente, o espectro de energia dos prótons emergentes apresentava picos associados às camadas nucleares, de onde os prótons eram ejetados. Além disso, combinando a energia e a distribuição angular dos prótons emergentes era possível determinar a distribuição dos momentos nas camadas individuais. Os muitos experimentos e cálculos realizados em vários laboratórios (Uppsala, Chicago, Harvard, Berkeley, entre outros) para investigar os vários aspectos desse fenômeno validaram a técnica de espalhamento quase-livre para o estudo da estrutura nuclear.

Na segunda metade dos anos 1960, os grandes avanços na área vieram dos laboratórios. Experimentos (p, $2 \mathrm{p}$ ) foram realizados em altas energias, até $1 \mathrm{GeV}$, com núcleos pesados, até $\mathrm{A}=209$, e avanços experimentais foram obtidos com os complicados experimentos (e,e'p), sobretudo no que se refere à resolução das medidas.

Nos últimos artigos publicados por Gerhard e colaboradores nessa área, eles propõem o uso de prótons polarizados para investigar o acoplamento spin-órbita em experimentos (p, 2p) [15, 39]. Os resultados teóricos do grupo do IF-UFRGS foram confirmados por experimentos realizados no acelerador de partículas TRIUMF, no Canadá [40].

\section{Epílogo}

No início da vida profissional de Gerhard Jacob, o gestor e o cientista atuaram simultaneamente. Quando assumiu o cargo de professor na Faculdade de Filosofia, juntamente com Darcy Dillenburg, ele teve que se envolver com a criação do Instituto de Física e com a contratação de um pesquisador experiente no exterior. Os brasileiros com perfis para a condução de pesquisa de ponta estavam comprometidos com os primeiros projetos de suas instituições (CBPF e USP). Foi um período difícil para os dois jovens pretendentes à carreira científica. Exerceram funções de gestor até que acharam Theodor Maris. O caminho para a pesquisa começou a ficar claro e eles começaram suas atividades de pesquisa, mas jamais se afastaram de atividades de gestão. Era a responsabilidade de quem estava à frente da criação de uma instituição de pesquisa em Física que viria a ser referência no país. Gerhard não passou mais do que 18 anos dedicado à pesquisa e sempre foi reconhecido pela sua capacidade como gestor, razão pela qual exerceu inúmeros cargos adminis- 
trativos e assessorou diversos órgãos governamentais ao longo de toda sua vida acadêmica.

Embora relativamente curta, sua carreira estritamente científica também foi claramente reconhecida pela comunidade pertinente. Por exemplo, não conheço nenhum caso na Física de alguém que tenha sido eleito para a Academia Brasileira de Ciências, no mesmo ano de sua defesa da tese de Cátedra ou de doutorado. Isso ocorreu em 1965.

Finalmente, como disse no início do artigo, em termos de impacto internacional de seu trabalho, cabe destacar que seu artigo de 1966, publicado na Reviews of Modern Physics [12], foi, entre 1973 e 1978, o artigo publicado no Terceiro Mundo mais citado por cientistas do Primeiro Mundo.

\section{Agradecimentos}

Ao prof. Luiz Fernando Ziebell, do IF-UFRGS pela leitura e pelos comentários ao manuscrito.

\section{Material Suplementar}

O seguinte material suplementar está disponível online:

Figure S1 - Carta de Roberto Salmeron Darcy Dillenburg e Gerhard Jacob, 1958.

Figure S2 - Carta de Gerard Hepp a Roberto Salmeron, 1958.

\section{Referências}

[1] C.A. dos Santos, in: Instituto de Física da UFRGS. 50 Anos de Inovação Científica, Pedagógica e Tecnológia. (Editora da UFRGS, Porto Alegre, 2013).

[2] D. Dillenburg and G. Jacob, in: Instituto de Física da UFRGS 50 Anos Inovação Científica, Pedagógica e Tecnológica (2013), p. 83.

[3] C.A. dos Santos, Rev. Bras. Ensino Física 39, e2601 (2017).

[4] J. Eichler and G. Jacob, Zeitschrift Für Phys. 157, 286 (1959).

[5] C.A. dos Santos, Rev. Bras. Ensino Física 35, 1607 (2013).

[6] A.M.R. Andrade, Físicos, Mésons e Política. A Dinâmica Da Ciência Na Sociedade (Hucitec, São Paulo, 1999).

[7] D. Dillenburg and G. Jacob, in: Curr. Top. Nucl. Phys. Quandum F. Theory, editado por D. Dillenburg, G. Jacob and C. Vasconcellos (Editora da UFRGS, Porto Alegre, 1994), pp. 11-17.

[8] P.M. Mors, V. E. Herscovitz and G. Jacob, Rev. Bras. Física 7, 283 (1977).

[9] G. Jacob and T.A.J. Maris, Phys. Rev. Lett. 5, 210 (1960).

[10] T.A. Brody, G. Jacob and M. Moshinsky, Nucl. Phys. 17, 16 (1960).

[11] G. Jacob and T.A.J. Maris, Nucl. Phys. 20, 440 (1960).

[12] G. Jacob and T.A.J. Maris, Rev. Mod. Phys. 38, 121 (1966).

[13] T. Berggren and G. Jacob, Phys. Lett. 1, 258 (1962).
[14] T. Berggren, G.E. Brown and G. Jacob, Phys. Lett. 1, 88 (1962)

[15] G. Jacob, T.A.J. Maris and M. R. Teodoro, Nucl. Phys. A257, 517 (1976).

[16] E.U. Baranger, Phys. Today 26, 34 (1973).

[17] I. Talmi, Front. Phys. 13, 132103 (2018).

[18] W.M. Elsasser, J. Phys. Radium. 4, 549 (1933).

[19] W.M. Elsasser, J. Phys. Radium 5, 389 (1934).

[20] W.M. Elsasser, J. Phys. Radium 5, 635 (1934).

[21] W. M. Elsasser, Memoirs of a Physicist in the Atomic Age (Science History Publications, New York, 1979).

[22] M. Goeppert-Mayer, The shell model, disponível em https://www.nobelprize.org/uploads/2018/06/mayerlecture.pdf, acessado em 02/11/2019.

[23] J. H.D. Jensen, Glimpses at the history of the nuclear structure theory, disponível em https://www.nobelprize.org/uploads/2018/06/jensen-lecture.pdf, acessado em 02/11/2019.

[24] J. H. Bartlett, Nature 130, 165 (1932).

[25] H. Kragh, Quantum Generations: A History of Physics in the Twentieth (Princeton University Press, Princeton, 2002).

[26] G. Gamow, Proc. R. Soc. Lond. A 126, 632 (1930).

[27] N. Bohr and J. Wheeler, Phys. Rev. (1939).

[28] N. Bohr, Nature 137, 344 (1936).

[29] W.M. Elsasser, Rev. Mod. Phys. 28, 135 (1956).

[30] M.G. Mayer and E. Teller, Phys. Rev. 76, 1226 (1949).

[31] O. Chamberlain and E. Segrè, Phys. Rev. 87, 81 (1952).

[32] P.A. Wolff, Phys. Rev. 87, 434 (1952).

[33] R. Serber, Phys. Rev. 72, 1114 (1947).

[34] T.A.J. Maris, P. Hillman and H. Tyren, Nucl. Phys. 7, 1 (1958)

[35] A.H. Compton, Phys. Rev. 21, 483 (1923).

[36] M.T. Hütt, A. I. L'vov, A. I. Milstein and M. Schumcher, Phys. Rep. 323, 457 (2000)

[37] G. Jacob and T.A.J. Maris, Rev. Mod. Phys. 45, 6 (1973).

[38] G. Jacob and T.A.J. Maris, Nucl. Phys. 32, 139 (1962).

[39] G. Jacob, T.A.J. Maris, C. Schneider and M. R. Teodoro, Phys. Lett. 45B, 181 (1973).

[40] P. Kitching, C.A. Miller W.C. Olsen, D. A. Hutcheon, W. J. McDonald and A. W. Stetz, Nucl. Phys. A340, $423(1980)$. 